\title{
Kajian Tempat Pengolahan Sampah Terpadu (TPST) Gunung Bahagia, Kota Balikpapan
}

\author{
Widya Indira Cahya dan Ellina Sitepu Pandebesie \\ (ITS) \\ e-mail:widyawic@gmail.com; ellina@its.ac.id
}

Departemen Teknik Lingkungan, Fakultas Teknik Sipil dan Perencanaan, Institut Teknologi Sepuluh Nopember

\begin{abstract}
Abstrak - Timbulan sampah Kota Balikpapan pada tahun 2015 mencapai 400 ton per hari. Salah satu program yang diharapkan dapat mengurai permasalahan sampah yaitu dengan membangun Tempat Pengolahan Sampah Terpadu (TPST). TPST diharapkan dapat mengubah sistem pengelolaan sampah menjadi terdesentralisasi, yaitu sistem pengelolaan pada areal hulu. TPST dapat mengurangi tingginya timbulan sampah di TPA. Data yang digunakan dalam penelitian ini meliputi data primer, yaitu hasil pengukuran komposisi dan kuantitas sampah serta jenis dan jumlah fasilitas pengolahan sampah. Data sekunder yaitu jumlah penduduk daerah pelayanan, kuantitas sampah selama setahun terakhir, daerah pelayanan TPST, serta data finansial TPST. Perhitungan kuantitas sampah menggunakan metode load-count dan weightvolume analysis. Pengambilan sampel untuk perhitungan komposisi dengan mengambil $\pm 100 \mathrm{~kg}$ sampah yang akan dianalisis susunan masing-masing komponen sampah yang dinyatakan dalam \% berat. Kesetimbangan massa dianalisis menggunakan nilai recovery factor dengan menganalisis secara cermat aliran sampah masuk, sampah diolah, dan sampah yang menjadi residu. Dalam analisis finansial, kriteria ekonomi yang digunakan adalah Net Present Value (NPV). Kuantitas sampah yang diolah setiap hari di TPST Gunung Bahagia adalah 35 $\mathrm{m}^{3}$ /hari atau setara dengan 3,9 ton/hari. Rata-rata sampah terjual sebesar $3.265,89 \mathrm{~kg} / \mathrm{hari}$ dan total residu ke TPA sebesar 605,79 kg/hari. Perhitungan kelayakan finansial mendapatkan nilai NPV>0 sehingga operasi TPST dipandang layak. Proyeksi pelayanan TPST menunjukkan bahwa TPST dapat meningkatkan kapasitas pelayanannya hingga tahun 2033 dengan kapasitas $91,7 \mathrm{~m}^{3} /$ hari setara dengan 9,9 ton/hari.
\end{abstract}

Kata Kunci-Analisis Ekonomi, Analisis Teknis, Balikpapan, Gunung Bahagia, Tempat Pengolahan Sampah Terpadu.

\section{PENDAHULUAN}

$\mathrm{P}$ ADA tahun 2012 tercatat potensi sampah Kota Balikpapan sebesar 316 ton/hari dan terakhir sebesar 400 ton/hari pada tahun 2015 [1]. Berbagai upaya dilakukan pemerintah Kota Balikpapan demi tercapainya target Kementerian Pekerjaan Umum dan Perumahan Rakyat pada tahun 2019 (100\% akses air bersih, 0\% pemukiman kumuh, $100 \%$ akses sanitasi layak). Salah satunya dengan mengeluarkan Peraturan Daerah No. 13 Tahun 2015 tentang Pengelolaan Sampah Rumah Tangga dan Sampah Sejenis Sampah Rumah Tangga. Sebagai realisasi peraturan daerah tersebut, salah satu program yang diharapkan dapat mengurai permasalahan sampah yaitu dengan membangun Tempat Pengolahan Sampah Terpadu (TPST).

Kota Balikpapan juga harus mengambil langkah untuk mereduksi jumlah sampah agar masa penggunaan Tempat Pemrosesan Akhir (TPA) Sampah Manggar dapat diperpanjang. Kehadiran TPST diharapkan dapat menjadikan sistem pengelolaan sampah menjadi terdesentralisasi, yaitu sistem pengelolaan pada areal hulu atau penghasil sampah pertama [2]. Sampah telah menjadi suatu permasalahan sehingga pengelolaannya perlu dilakukan secara komprehensif agar memberikan manfaat secara ekonomi, sehat bagi masyarakat, aman bagi lingkungan, serta dapat mengubah perilaku masyarakat [3]. Sejauh ini, masyarakat masih memandang sampah dari sisi negatif. Padahal tidak semua sampah harus dimusnahkan, melainkan cara pandang yang harus diubah, dimana sampah dilihat sebagai bahan baku yang masih dapat diolah dan merupakan sumber pendapatan yang potensial. TPST umumnya menampung segala jenis sampah anorganik yang dihasilkan oleh masyarakat, mulai dari plastik, alumunium, seng, kertas, besi, tembaga, kuningan, hingga botol kaca [4].

Sampah yang berasal dari seluruh wilayah Kota Balikpapan dibuang pada satu TPA yang berlokasi di Kelurahan Manggar, Kecamatan Balikpapan Timur. Jika tidak ada upaya untuk mereduksi sampah kota, maka masa pakai TPA akan sulit diperpanjang mengingat TPA telah berusia 10 tahun lebih. Jika TPA Manggar pada saatnya penuh sementara Pemerintah Kota Balikpapan belum bisa mencari lahan TPA yang baru, kondisi ini akan mengakibatkan terjadinya pencemaran lingkungan akibat penumpukan sampah di wilayah kota. Fakta yang terlihat sehari-hari menunjukkan bahwa umumnya sampah-sampah domestik ataupun industri, organik maupun anorganik, dibuang dalam satu bak sampah yang sama dan tercampur berbagai komposisi [5]. Salah satu upaya untuk mengatasi permasalahan sampah di Kota Balikpapan tersebut adalah dengan dibangunnya TPST Gunung Bahagia. TPST Gunung Bahagia baru berjalan sejak Februari 2016 sehingga belum ditemukan adanya penelitian ditinjau dari aspek teknis dan finansial, serta potensi pengembangan wilayah pelayanan TPST. Tujuan dari penelitian ini adalah mengkaji tingkat daur ulang sampah pada akhir tahun rencana dan menentukan kelayakan finansial dari pengelolaan sampah di TPST Gunung Bahagia.

\section{METODE PENELITIAN}

\section{A. Tahap Pengumpulan Data}

Data yang dibutuhkan dalam penelitian ini meliputi data primer dan data sekunder. Data primer diperoleh dari pengamatan dan pengukuran langsung di lapangan.

Data primer dalam penelitian ini, antara lain:

1. Volume sampah yang diolah di TPST Gunung Bahagia.

Volume sampah dihitung berdasarkan metode load-count analysis dan weight volume analysis. Menghitung total volume sampah yang masuk ke TPST disesuaikan dengan volume bak kendaraan pengumpul. Pengambilan sampah berdasarkan volume dan berat sampah di kendaraan pengumpul 8 hari berturut-turut [6]. Untuk perhitungan berat 
sampah di kendaraan pengumpul dilakukan penimbangan terlebih dahulu menggunakan bantuan jembatan timbang yang berlokasi di TPA Manggar. Diambil 3 unit pick up sebagai sampel. Berat sampah didapatkan dari berat pick up berisi sampah dikurangi berat pick up kosong. Berat sampah rata-rata dari ketiga sampel pick up tersebut kemudian dikalikan dengan jumlah kendaraan yang masuk ke TPST. Hal ini bertujuan untuk mengetahui berat total sampah yang masuk ke TPST. Penentuan volume sampah dihitung berdasarkan volume kendaraan pengumpul menggunakan persamaan perhitungan volume (panjang $\mathrm{x}$ lebar $\mathrm{x}$ tinggi). Setelah mengetahui volume dan berat, maka dapat menghitung densitas sampah (dalam satuan $\mathrm{kg} / \mathrm{m}^{3}$ ) dengan menggunakan persamaan perhitungan berat jenis sampah [7].

2. Komposisi sampah yang diolah di TPST Gunung Bahagia.

Analisis komposisi sampah dilakukan untuk mengetahui persentase komponen sampah yang diolah setiap harinya di TPST. Analisis ini dilakukan bersamaan dengan pengukuran volume sampah. Komposisi sampah ditentukan dari $100 \mathrm{~kg}$ sampah per sampel yang masuk melalui kendaraan pengumpul dan telah diketahui berat atau berat jenisnya. Komposisi ini berdasarkan masing-masing komponen sampah yang ditimbang dan ditentukan persentase per komponennya dari berat total sampah yang masuk. Jumlah sampah yang dianalisis diambil menggunakan metode perempatan untuk memperoleh sampel komposisi sampah sebanyak $100 \mathrm{~kg}$ [7].

3. Jenis dan jumlah fasilitas pengolahan sampah.

Fasilitas ini terkait kendaraan pengumpul, kontainer wadah jaring, conveyor belt, dan lain-lain. Data fasilitas digunakan untuk analisis finansial.

4. Jumlah SDM dan organisasi TPST.

Jumlah SDM antara lain tenaga pilah, supir dan ABK kendaraan pengumpul, tenaga administrasi, security, dan mekanik. Data tersebut berguna untuk analisis finansial.

5. Jumlah residu yang dihasilkan.

Jumlah residu berdasarkan analisis kesetimbangan bahan yang dihitung berdasarkan sampah yang masuk ke TPST.

Data sekunder diperoleh dari TPST Gunung Bahagia maupun studi literatur. Data sekunder dalam penelitian ini, antara lain:

1. Data kuantitas sampah yang diolah setahun terakhir. Data ini berguna untuk mengetahui reduksi sampah di TPST Gunung Bahagia.

2. Jumlah penduduk dan daerah pelayanan TPST. Data ini berguna untuk analisis aspek teknis dengan mengkaji proyeksi pengembangan pelayanan TPST.

3. Peta Kecamatan Balikpapan Selatan. Data ini berguna untuk menyesuaikan letak kondisi eksisting TPST dengan daerah pelayanan TPST.

4. Pemasukan dan pengeluaran operasional TPST serta harga penjualan lapak dan kapasitas pembelian pengepul. Data ini berguna untuk analisis finansial.

\section{B. Tahap Analisis Data}

Data yang terkumpul digunakan untuk menganalisis permasalahan yang telah dirumuskan. Analisis dilakukan melalui dua aspek, yaitu teknis dan finansial. Secara garis besar, bahasan yang dikembangkan setiap aspek, antara lain: 1) Aspek Teknis

- Data volume dan komposisi sampah yang diolah oleh TPST Gunung Bahagia beserta produk dan residu yang dihasilkan berguna untuk menghitung analisis kesetimbangan massa. Analisis kesetimbangan massa digunakan untuk mengetahui besarnya sampah yang tereduksi di TPST. Analisis ini mengacu pada analisis komposisi sampah $(100 \mathrm{~kg})$ setelah dilakukan pemilahan untuk setiap komponen yang memiliki nilai jual/daur ulang dikurangi residu. Untuk setiap komponen sampah, dihitung nilai recovery factor (RF) yang ditentukan dari kriteria sampah yang memiliki nilai jual yang diketahui oleh pekerja pemilah. Setelah mengetahui jumlah sampah yang diolah dan persentase RF yang dimiliki setiap sampah, selanjutnya menggambar diagram kesetimbangan massa. Diagram ini menggambarkan jumlah sampah yang diolah, dijual, serta yang dibuang ke TPA.

- Proyeksi penduduk. Setelah mengetahui jumlah penduduk di daerah pelayanan, selanjutnya menghitung proyeksi penduduk menggunakan metode least square karena metode ini memiliki nilai $\mathrm{r}$ paling mendekati 1 . Selanjutnya dilakukan proyeksi timbulan sampah. Nilai timbulan yang didapatkan dijadikan acuan perhitungan timbulan pada tahun proyeksi (10 tahun).

2) Aspek Finansial.

Data yang diperlukan adalah data pemasukan serta pengeluaran selama operasional TPST. Perhitungan analisis finansial menggunakan metode Net Present Value (NPV). Data pemasukan yang dimaksud meliputi:

- Hasil penjualan lapak sampah, dan

- Biaya retribusi pelanggan TPST.

Data pengeluaran yang dimaksud meliputi:

- Biaya listrik;

- Gaji pegawai beserta insentif;

- Kebutuhan kantor;

- Kebutuhan BBM; dan

- Perbaikan dan perawatan mesin.

\section{HASIL DAN PEMBAHASAN}

\section{A. Berat, Volume, dan Berat Jenis Sampah}

Untuk melakukan perhitungan timbulan sampah, terlebih dahulu dilakukan pencatatan berat sampah dari kendaraan pengumpul yang masuk ke TPST. Pencatatan berat dilakukan dengan bantuan jembatan timbang yang berada di TPA Manggar dengan mengambil sampel 3 unit pick up TPST setiap harinya. Pengukuran volume menggunakan alat meteran dengan menghitung panjang dan lebar kendaraan pengumpul, serta tinggi sampah [8].

Peningkatan volume sampah biasa terjadi pada hari Senin karena pada hari Minggu tidak ada aktivitas pengumpulan dari halte sampah maupun aktivitas di TPST sehingga kemungkinan warga menyimpan sampahnya selama dua hari di rumah. Tabel 1 menunjukkan data berat dan volume sampah yang masuk. Dengan mengetahui berat dan volume sampah, dapat dihitung berat jenis (densitas) sampah yang masuk ke TPST.

Tabel 1.

Hasil Pencatatan Berat dan Pengukuran Volume Sampah di TPST Gunung Bahagia 


\begin{tabular}{ccrrc}
\hline Hari & $\begin{array}{c}\text { Jumlah } \\
\text { Kendaraan } \\
\text { (unit/hari) }\end{array}$ & $\begin{array}{c}\text { Berat } \\
\text { Sampah } \\
\text { (kg/unit) }\end{array}$ & $\begin{array}{c}\text { Berat } \\
\text { Total } \\
\text { (kg/hari) }\end{array}$ & $\begin{array}{c}\text { Volume } \\
\text { Sampah } \\
\text { (m3/hari) }\end{array}$ \\
\hline 1 & 11 & 400,00 & 4.400 & 36 \\
2 & 11 & 331,50 & 3.647 & 34 \\
3 & 10 & 349,00 & 3.490 & 34 \\
4 & 10 & 320,00 & 3.200 & 31 \\
5 & 11 & 409,00 & 4.499 & 35 \\
6 & 10 & 351,00 & 3.510 & 33 \\
7 & 11 & 418,00 & 4.598 & 37 \\
8 & 10 & 363,00 & 3.630 & 36 \\
\hline \multicolumn{5}{c}{ Rata-rata } \\
\hline
\end{tabular}

Perhitungan berat jenis sampah sebagai berikut:

Densitas $(\rho)=$ Berat $/$ Volume

Densitas $(\rho)=$ Berat sampah rata-rata / Volume sampah rata-rata

Densitas $(\rho)=3.871,69 \mathrm{~kg} / 35 \mathrm{~m}^{3}=110,62 \mathrm{~kg} / \mathrm{m}^{3}$

\section{B. Analisis Komposisi Sampah}

Analisis komposisi dilakukan bersamaan dengan pengukuran volume sampah. Komposisi diambil secara acak dari jumlah kendaraan pengumpul di TPST. Kuantitas sampah diambil sebagai sampel sebanyak $100 \mathrm{~kg}$ (metode perempatan). Tabel 2 dan 3 menunjukkan rata-rata persentase komponen sampah yang dihitung selama 8 hari. Setelah mengetahui berat rata-rata sampah dan persentase yang diolah setiap hari, selanjutnya menghitung nilai RF.

Tabel 2.

Hasil Pengukuran Komposisi Sampah yang Dapat Dijual/Didaur Ulang (1)

\begin{tabular}{|c|c|c|c|c|c|c|c|}
\hline \multirow{2}{*}{ No. } & \multirow{2}{*}{ Jenis Sampah } & \multicolumn{4}{|c|}{ Berat Sampah (kg) } & \multirow{2}{*}{$\begin{array}{l}\text { Berat Rata- } \\
\text { rata per hari } \\
(\mathrm{kg})\end{array}$} & \multirow{2}{*}{$\begin{array}{l}\text { Persentase } \\
\text { (\%) }\end{array}$} \\
\hline & & Hari 1 & Hari 2 & Hari 3 & Hari 4 & & \\
\hline 1 & Kertas 1 & 22,75 & 21,50 & 6,70 & 24,35 & $\begin{array}{r}\mid \mathrm{ng} / \\
16,79\end{array}$ & 16,44 \\
\hline 2 & Kertas 2 & 32,50 & 27,30 & 28,70 & 27,50 & 29,50 & 28,89 \\
\hline 3 & Gelas plastik & 1,55 & 1,80 & 2,40 & 1,68 & 2,37 & 2,32 \\
\hline 4 & Botol plastik & 12,50 & 12,30 & 22,76 & 19,00 & 16,17 & 15,84 \\
\hline 5 & Plastik nonbotol & 19,00 & 18,50 & 12,80 & 9,75 & 18,47 & 18,09 \\
\hline 6 & Kaleng/besi & 6,50 & 7,80 & 13,85 & 7,50 & 8,63 & 8,46 \\
\hline 7 & Botol kaca & 4,40 & 3,50 & 2,25 & 1,45 & 2,04 & 2,00 \\
\hline 8 & B3 \& lainnya & 5,70 & 7,10 & 12,30 & 10,65 & 8,13 & 7,96 \\
\hline \multicolumn{2}{|c|}{ Total Berat Sampah } & 104,90 & 99,80 & 101,76 & 101,88 & 102,10 & 100,00 \\
\hline
\end{tabular}

Catatan: * Kertas 1: HVS, koran, kertas buram/warna

** Kertas 2: majalah, kardus, dupleks

Tabel 3.

Hasil Pengukuran Komposisi Sampah yang Dapat Dijual/Didaur Ulang (2)

\begin{tabular}{|c|c|c|c|c|c|c|c|}
\hline \multirow[b]{2}{*}{ No. } & \multirow{2}{*}{ Jenis Sampah } & \multicolumn{4}{|c|}{ Berat Sampah (kg) } & \multirow{2}{*}{$\begin{array}{l}\text { Berat Rata- } \\
\text { rata per hari } \\
(\mathrm{kg})\end{array}$} & \multirow{2}{*}{$\begin{array}{c}\text { Persentase } \\
(\%)\end{array}$} \\
\hline & & Hari 5 & Hari 6 & Hari 7 & Hari 8 & & \\
\hline 1 & Kertas 1 & 17,80 & 16,24 & 6,90 & 18,04 & 16,79 & 16,44 \\
\hline 2 & Kertas 2 & 37,84 & 24,80 & 26,86 & 30,48 & 29,50 & 28,89 \\
\hline 3 & Gelas plastik & 5,80 & 1,81 & 2,45 & 1,50 & 2,37 & 2,32 \\
\hline 4 & Botol plastik & 15,66 & 18,10 & 14,55 & 14,50 & 16,17 & 15,84 \\
\hline 5 & Plastik nonbotol & 13,22 & 18,51 & 30,00 & 25,95 & 18,47 & 18,09 \\
\hline 6 & Kaleng/besi & 4,13 & 9,83 & 13,55 & 5,90 & 8,63 & 8,46 \\
\hline 7 & Botol kaca & 3,50 & 1,25 & 0,00 & 0,00 & 2,04 & 2,00 \\
\hline 8 & B3 \& lainnya & 6,75 & 11,31 & 5,60 & 5,61 & 8,13 & 7,96 \\
\hline \multicolumn{2}{|c|}{ Total Berat Sampah } & 104,70 & 101,85 & 99,91 & 101,98 & 102,10 & 100,00 \\
\hline
\end{tabular}

* Kertas 2: majalah, kardus, dupleks

Komponen sampah kertas 2 paling banyak dihasilkan karena sampah kardus, karton seperti kotak susu, teh kotak, dan kemasan lainnya, serta majalah seringkali dikonsumsi oleh masyarakat area pemukiman.

\section{C.Analisis Mass Balance dan Potensi Daur Ulang Sampah}

Analisis mass balance digunakan untuk mengetahui besarnya sampah yang tereduksi di TPST Gunung Bahagia. Analisis ini mengacu pada hasil analisis komposisi sampah.
Hasil RF ditentukan dari kriteria sampah yang memiliki nilai jual yang telah diketahui oleh pegawai TPST. Berdasarkan kriteria yang diberikan oleh pekerja pemilah di TPST Gunung Bahagia, hanya jenis B3 dan lainnya yang tidak memiliki nilai RF. Sampah B3 dan lainnya ini kemudian diangkut sebagai residu ke TPA Manggar. Hasil perhitungan RF dapat dilihat pada Tabel 4.

Tabel 4.

Hasil Analisis Recovery Factor di TPST Gunung Bahagia

\begin{tabular}{llrrr}
\hline No. & Komposisi & $\begin{array}{c}\text { Rata-rata } \\
\text { berat per } \\
\text { hari (kg) }\end{array}$ & $\begin{array}{c}\text { Rata-rata } \\
\text { termanfaatkan } \\
(\mathbf{k g})\end{array}$ & RF (\%) \\
\hline 1 & Kertas 1 & 16,79 & 15,28 & $91 \%$ \\
2 & Kertas 2 & 29,50 & 25,67 & $87 \%$ \\
3 & Gelas plastik & 2,37 & 2,13 & $90 \%$ \\
4 & Botol plastik & 16,17 & 15,20 & $94 \%$ \\
5 & Plastik nonbotol & 18,47 & 18,47 & $100 \%$ \\
6 & Kaleng/besi & 8,63 & 7,33 & $85 \%$ \\
7 & Botol kaca & 2,04 & 2,04 & $100 \%$ \\
8 & B3 \& lainnya & 8,13 & 0 & $0 \%$ \\
\hline \multicolumn{6}{c}{ Total } & $\mathbf{1 0 2 , 1 0}$ & $\mathbf{8 6 , 1 2}$ & $\mathbf{8 4 \%}$ \\
\hline
\end{tabular}

Komponen kertas tidak dapat didaur ulang secara keseluruhan karena beberapa kertas rusak seperti basah terkena air atau sisa makanan yang menimbulkan bau tidak sedap. Komponen gelas plastik, kaleng, dan botol plastik tidak dapat didaur ulang secara keseluruhan karena beberapa gelas, kaleng, dan botol plastik pecah dan rusak. Keseluruhan dari komponen B3 dan lainnya, baik baterai maupun bola lampu, tidak dapat didaur ulang karena merupakan limbah yang berbahaya sehingga menjadi residu.

Setelah mengetahui jumlah sampah yang diolah dan berapa persen RF yang dimiliki masing-masing komponen, selanjutnya menggambar diagram mass balance. Diagram ini menggambarkan jumlah sampah yang diolah ataupun dijual, serta yang akan dibuang ke TPA. Gambar diagram mass balance dapat dilihat pada Gambar 1. Untuk mengetahui apakah jumlah kesetimbangan bahan sesuai, maka penjumlahan persentase sampah yang termanfaatkan dan residu harus sama dan $100 \%$. Berdasarkan perhitungan persen reduksi, diketahui bahwa saat ini kehadiran TPST dapat mereduksi sampah di dua kelurahan di Balikpapan Selatan sebesar $84,35 \%$ per hari.

\section{D.Pengembangan Pelayanan TPST Gunung Bahagia}

Setelah mengetahui jumlah penduduk daerah yang terlayani TPST, selanjutnya menghitung proyeksi penduduk untuk 10 tahun. Proyeksi penduduk menggunakan metode least square. Target pelayanan disesuaikan dengan target Kementerian Pekerjaan Umum dan Perumahan Rakyat untuk tahun 2019, yaitu sebesar $100 \%$ akses sanitasi layak. Berdasarkan data TPST Gunung Bahagia (2017) saat ini TPST melayani 7.561 KK dengan rata-rata jumlah penduduk per KK adalah 4 orang. 


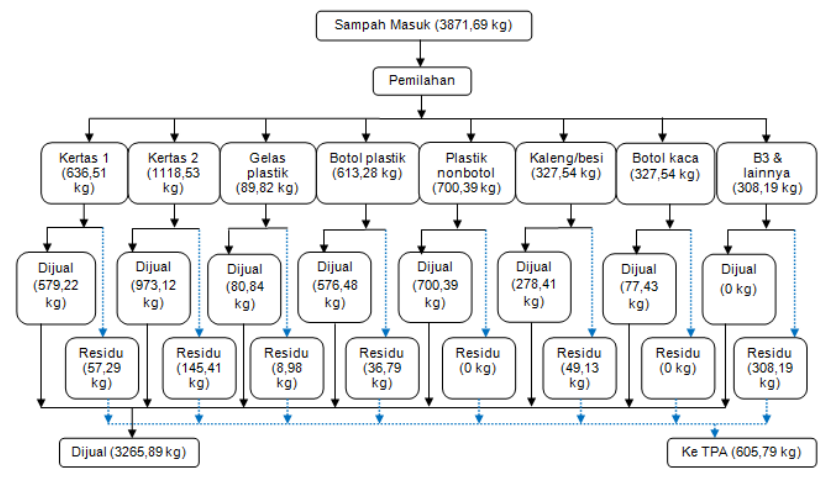

Gambar 1. Diagram Mass Balance Sampah di TPST Gunung Bahagia.

Persentase pelayanan pada tahun 2017 adalah sebesar $54,35 \%$. Maka diperlukan besarnya kenaikan pelayanan $4,6 \%$ per tahun agar bisa melayani $100 \%$ dari total jumlah penduduk tahun 2027.

Saat sampling diketahui bahwa sampah yang masuk sebesar $35 \mathrm{~m}^{3} /$ hari terdiri dari sampah kering (bernilai jual/daur ulang). Dengan acuan tersebut, didapatkan perhitungan sebagai berikut:

Volume sampah $2017=35 \mathrm{~m}^{3} /$ hari

Jumlah penduduk $2017=55.642$ jiwa

Penduduk terlayani $2017=30.244$ jiwa

Timbulan rata-rata/orang $=$ Volume sampah / Penduduk terlayani

$=35 \mathrm{~m}^{3} / 30.244$ jiwa

$=1,2 \times 10^{-3} \mathrm{~m}^{3} /$ hari

$=1,2 \mathrm{~L} /$ orang/hari

Diketahui bahwa timbulan sampah adalah 1,2 L/orang/hari. Nilai ini dijadikan acuan perhitungan timbulan pada tahun proyeksi. Nilai diasumsikan tetap karena pihak pemerintah telah menggalakkan upaya reduksi sampah melalui kader-kader lingkungan. Selain itu, telah ada pemahaman mengenai pemilahan yang baik dari masyarakat. Di samping itu, juga mempertimbangkan kapasitas maksimal penerimaan sampah oleh TPST sebesar 10 ton/hari.

Wilayah pelayanan eksisting mencakup dua kelurahan, yaitu Kelurahan Gunung Bahagia dan Kelurahan Sepinggan Baru dengan timbulan rata-rata 3,9 ton/hari. Berdasarkan data TPST Gunung Bahagia (2016) kapasitas maksimal penerimaan sampah adalah 10 ton/hari. Terlihat pada Tabel 5 bahwa pelayanan TPST dapat dimaksimalkan hingga tahun 2033 dengan jumlah sampah masuk sebesar $9.930 \mathrm{~kg} / \mathrm{hari}$ atau setara $91,7 \mathrm{~m}^{3} /$ hari. Jika pada tahun 2017 timbulan sebesar $35 \mathrm{~m}^{3}$ /hari, maka ini menunjukkan bahwa TPST saat ini baru menggunakan 35\% dari kapasitas maksimalnya.

Untuk memaksimalkan pelayanan, TPST Gunung Bahagia dapat menambah wilayah pelayanan sesuai rencana pengembangan, yaitu Kelurahan Sungai Nangka. Hal ini dikarenakan letaknya dekat dengan lokasi TPST sehingga dapat mengoptimalkan proses pengumpulan sampah. Demi terselenggaranya pelayanan pengumpulan sampah yang optimal, TPST perlu menambah 2 unit pick up untuk mengumpulkan sampah dari halte sampah di wilayah pelayanan yang baru menuju TPST. Jumlah supir pick up dan tenaga pengumpul tambahan sebanyak 6 orang serta tenaga pilah sebanyak 24 orang. Hal ini disesuaikan dengan kapasitas maksimal pick up pengumpul, yaitu $5,3 \mathrm{~m}^{3}$ dan ritasi 3 trip/hari.

Tabel 5.
Hasil Perhitungan Pengembangan Pelayanan TPST Gunung Bahagia

\begin{tabular}{|c|c|c|c|c|}
\hline \multirow{2}{*}{ Tahun } & $\begin{array}{c}\text { Penduduk } \\
\text { dilayani (jiwa) }\end{array}$ & $\begin{array}{c}\text { Timbulan } \\
\text { (Lorg.hari) }\end{array}$ & $\begin{array}{c}\text { Total timbulan } \\
\text { (Lhari) }\end{array}$ & \multirow{2}{*}{$\begin{array}{c}\text { Timbulan } \\
\text { Sampah } \\
\left(m^{3} / h a r i\right)\end{array}$} \\
\hline & (a) & (b) & $(a \times b)$ & \\
\hline 2017 & 30.241 & 1,2 & $36.289,73$ & 36,3 \\
\hline 2018 & 33.457 & 1,2 & $40.148,39$ & 40,1 \\
\hline 2019 & 36.789 & 1,2 & $44.146,88$ & 44,1 \\
\hline 2020 & 40.241 & 1,2 & $48.289,26$ & 48,3 \\
\hline 2021 & 43.816 & 1,2 & $52.579,67$ & 52,6 \\
\hline 2022 & 47.519 & 1,2 & $57.022,38$ & 57,0 \\
\hline 2023 & 51.351 & 1,2 & $61.621,76$ & 61,6 \\
\hline 2024 & 55.319 & 1,2 & $66.382,32$ & 66,4 \\
\hline 2025 & 59.424 & 1,2 & $71.308,64$ & 71,3 \\
\hline 2026 & 63.671 & 1,2 & $76.405,47$ & 76,4 \\
\hline 2027 & 67.827 & 1,2 & $81.392,40$ & 81,4 \\
\hline 2028 & 69.184 & 1,2 & $83.020,63$ & 83,0 \\
\hline 2029 & 70.568 & 1,2 & $84.681,04$ & 84,7 \\
\hline 2030 & 71.979 & 1,2 & $86.374,66$ & 86,4 \\
\hline 2031 & 73.418 & 1,2 & $88.102,16$ & 88,1 \\
\hline 2032 & 74.887 & 1,2 & $89.864,20$ & 89,9 \\
\hline 2033 & 76.385 & 1,2 & $91.661,48$ & 91,7 \\
\hline
\end{tabular}

\section{E. Analisis Finansial}

Analisis finansial digunakan untuk mengetahui kelayakan suatu investasi. Analisis ini digunakan untuk memperoleh data yang optimum sebagai dasar kelayakan suatu proyek [9]. Untuk menghitung analisis finansial menggunakan metode NPV, dibutuhkan data pemasukan dan pengeluaran TPST. Biaya pemasukan adalah biaya yang berasal dari pihak luar TPST. Biaya pengeluaran adalah biaya yang dikeluarkan oleh TPST dalam menunjang operasional. Langkah awal dalam melakukan analisis adalah menghitung aliran kas (cash flow). Aliran kas diperoleh dari selisih pemasukan dan pengeluaran. Aliran Kas TPST per $\mathrm{m}^{3}$ tahun dapat dilihat pada Tabel 6 .

Tabel 6.

\begin{tabular}{|c|c|c|}
\hline \multicolumn{3}{|c|}{$\begin{array}{c}\text { Tabel } 6 . \\
\text { Aliran Kas TPST Per } \mathrm{m}^{3} \text { Per Tahun }\end{array}$} \\
\hline No. & Uraian & Jumlah (Rp) \\
\hline \multicolumn{3}{|c|}{ Pemasukan } \\
\hline 1 & Retribusi Pelanggan & 989.931 .070 \\
\hline \multirow[t]{2}{*}{2} & Penjualan Lapak & 113.861 .975 \\
\hline & Total Pemasukan & 1.103 .793 .045 \\
\hline \multicolumn{3}{|c|}{ Pengeluaran } \\
\hline 1 & Kebutuhan BBM & 328.049 .383 \\
\hline 2 & Perawatan Mesin & 42.057 .613 \\
\hline 3 & Biaya Listrik & 9.391 .510 \\
\hline 4 & Kebutuhan Kantor & 7.645 .473 \\
\hline 5 & Gaji Pegawai TPST & 577.126 .434 \\
\hline \multirow[t]{2}{*}{6} & Insentif Pegawai TPST & 130.679 .012 \\
\hline & Total Pengeluaran & 1.094 .949 .426 \\
\hline
\end{tabular}

Aliran kas per volume sampah yang masuk ke TPST akan dikalikan dengan jumah volume sampah per tahun hingga tahun 2027. Retribusi disesuaikan dengan Peraturan Daerah Kota Balikpapan No. 9 Tahun 2011 tentang Retribusi Jasa Umum. Besarnya retribusi untuk rumah tangga dibedakan menjadi 3 golongan, yaitu golongan A (kecil), golongan B (menengah), dan golongan C (besar). Tarif retribusi untuk golongan A sebesar Rp2.500,00 per bulan. Golongan B sebesar Rp3.750,00 per bulan. Golongan C sebesar Rp17.500,00 per bulan. Dari 8 komposisi sampah kering yang dipilah, hasil pilahan tersebut dipilah lagi menjadi jenis sampah yang bernilai jual. Dalam sebulan, rata-rata penjualan sebanyak satu hingga dua kali. Hal ini dikarenakan menunggu hasil olahan yang banyak sebelum diambil oleh pengepul. Setiap kali penjualan memperoleh pendapatan antara Rp3.800.000,00 hingga Rp7.800.000,00 
yang digunakan untuk insentif petugas TPST. Besaran gaji untuk setiap pegawai disesuaikan dengan jabatan dan upah minimum regional. Gaji pegawai mulai tahun 2018 hingga tahun-tahun berikutnya diasumsikan terkena inflasi sebesar 11,90\% (suku bunga Bank Indonesia per Maret 2017).

Tabel 7.

Perhitungan NPV Tahun 2017 Hingga Tahun 2021

\begin{tabular}{lrrrrr}
\hline Tahun & 2017 & 2018 & 2019 & 2020 & 2021 \\
\hline Pemasukan (Rp) & 1.952 .398 .177 & 2.001 .287 .303 & 2.051 .551 .188 & 2.103 .204 .521 & 2.155 .942 .143 \\
Pengeluaran (Rp) & 1.314 .233 .118 & 1.456 .148 .570 & 1.610 .041 .632 & 1.776 .863 .893 & 1.955 .973 .977 \\
Aliran Kas (Rp) & 638.165 .059 & 545.138 .733 & 441.509 .556 & 326.340 .627 & 199.968 .166 \\
Dicount Rate & $11,90 \%$ & $11,90 \%$ & $11,90 \%$ & $11,90 \%$ & $11,90 \%$ \\
\hline NPV (Rp) & 574.457 .700 & 441.730 .215 & 322.043 .996 & 214.274 .888 & 118.191 .441 \\
\hline
\end{tabular}

Tabel 8.

Perhitungan NPV Tahun 2022 Hingga Tahun 2027

\begin{tabular}{lrrrrr}
\hline Tahun & 2023 & 2024 & 2025 & 2026 & 2027 \\
\hline Pemasukan (Rp) & 3.129 .786 .770 & 3.203 .805 .169 & 3.279 .316 .742 & 3.356 .665 .091 & 3.434 .913 .720 \\
Pengeluaran (Rp) & 2.357 .583 .772 & 2.584 .535 .845 & 2.829 .313 .955 & 3.095 .405 .147 & 3.379 .700 .818 \\
Aliran Kas (Rp) & 772.202 .998 & 619.269 .325 & 450.002 .786 & 261.259 .944 & 55.212 .902 \\
Dicount Rate & $11,90 \%$ & $11,90 \%$ & $11,90 \%$ & $11,90 \%$ & $11,90 \%$ \\
\hline NPV (Rp) & 369.833 .899 & 266.980 .679 & 174.638 .705 & 91.268 .973 & 17.362 .647 \\
\hline
\end{tabular}

Tabel 9.

Penentuan Status Kelayakan TPST

\begin{tabular}{lr}
\hline Total NPV & 864.877 .057 \\
Modal Awal & 400.000 .000 \\
Status & Untung \\
Status Kelayakan & Layak \\
\hline
\end{tabular}

Setelah mengetahui aliran kas dari tahun 2017 hingga tahun 2027, selanjutnya adalah menghitung NPV setiap tahunnya. Sebelum menentukan status kelayakan, diperlukan nilai NPV per tahun yang akan disajikan pada Tabel 7 dan Tabel 8. Discount rate yang dikeluarkan oleh TPST Gunung Bahagia berdasarkan suku bunga pinjaman Bank Indonesia per Maret 2017 adalah sebesar 11,90\%. Setelah mengetahui aliran kas dan nilai NPV per tahun, selanjutnya menghitung NPV total tiap tahun. Pada tahun 2017 hingga tahun 2027 dapat dikatakan TPST mendapat keuntungan dengan total NPV sebesar Rp864.877.057,00. Hasil penentuan kelayakan dapat dilihat pada Tabel 9.

Direncanakan adanya kenaikan tarif retribusi setiap tiga tahun sekali agar tidak terjadi defisit selama 10 tahun ke depan. Kenaikan tarif retribusi pelanggan TPST direncanakan sebesar 15\% dari tarif awal pada tahun 2019, sebesar $30 \%$ pada tahun 2023 , dan sebesar $42 \%$ pada tahun 2027.
Nilai NPV pada perhitungan memperoleh hasil bahwa NPV $>0$ sehingga dengan demikian kegiatan TPST Gunung Bahagia dipandang layak.

\section{KESIMPULAN}

1. Timbulan pada tahun 2017 sebesar $35 \mathrm{~m}^{3} /$ hari atau setara 3,9 ton/hari menunjukkan bahwa TPST Gunung Bahagia saat ini baru menggunakan 35\% dari kapasitas maksimal sebesar 10 ton/hari. Kehadiran TPST saat ini dapat mereduksi sampah di dua kelurahan di Balikpapan Selatan sebesar $84,35 \%$ per hari.

2. Sampah kering yang masuk ke TPST Gunung Bahagia sebesar 3.871,69 kg/hari menghasilkan produk untuk penjualan lapak sebesar $3.265,89 \mathrm{~kg} /$ hari dan total residu ke TPA sebesar 605,79 kg/hari sehingga kesetimbangan massa sesuai.

3. Hasil analisis finansial menunjukkan bahwa pada volume sampah sebesar $35 \mathrm{~m}^{3} /$ hari pada tahun 2017 dan proyeksi 10 tahun sebesar $81,4 \mathrm{~m}^{3} /$ hari di tahun 2027 menunjukkan nilai NPV $>0$. Dengan demikian, kegiatan TPST dipandang layak.

4. Pelayanan TPST Gunung Bahagia dapat dikembangkan hingga tahun 2033 dengan kapasitas penerimaan 9,9 ton/hari atau setara $91,7 \mathrm{~m}^{3} /$ hari.

\section{DAFTAR PUSTAKA}

[1] Dinas Kebersihan Pertamanan dan Pemakaman Kota Balikpapan, "Laporan pengelolaan sampah kota Balikpapan," Balikpapan, 2015.

[2] Hardianto and S. N. Sedia, "Potensi reduksi dan potensi ekonomi sampah kering (Studi kasus: kecamatan Mandonga, kota Kendari)," J. Tek., vol. 10, no. 1, pp. 17-22, 2012.

[3] C. D. Sucipto, Teknologi pengelolaan daur ulang sampah. Yogyakarta: Gosyen Publishing, 2012.

[4] B. Prihatiningsih and F. Achmad, "Analisis sistem pengelolaan sampah melalui partisipasi adaptif masyarakat di kota Malang," Malang, 2013.

[5] A. Zubair and Haeruddin, "Studi Potensi daur ulang sampah di TPA Tamanggapa kota Makassar,” Makassar, 2012.

[6] Badan Standardisasi Nasional, "SNI 19-3964-1994 tentang Metode pengambilan dan pengukuran contoh timbulan dan komposisi sampah perkotaan," 1994.

[7] G. Tchobanoglous, H. Thiesen, and S. Vigil, Integrated solid waste management: Engineering Principles and management issues. New York: Mc Graw Hill Inc, 1993.

[8] S. Maryani, B. Rahadi, and N. Lusiana, "Kajian pengelolaan timbulan sampah ramah lingkungan di kabupaten Ponorogo," in Prosiding Seminar Nasional Waste Management I, 2012.

[9] I. W. Yansen and A. I Made, "Analisis finansial pengelolaan sampah di wilayah kecamatan Mengwi kabupaten Badung," $J$ Ilm. Tek. Sipil, vol. 16, no. 1, pp. 107-116, 2012. 